\title{
Editorial: Agroecosystems Facing Global Climate Change: The Search for Sustainability
}

\author{
José M. Mirás-Avalos ${ }^{1 *}$ and Philippe C. Baveye ${ }^{2}$ \\ ${ }^{1}$ Gl-1716, Proyectos y Planificación, Departamento de Ingeniería Agroforestal, Universidade de Santiago de Compostela, \\ Escola Politécnica Superior de Enxeñaría, Lugo, Spain, ${ }^{2}$ ECOSYS Unit, AgroParisTech, Université Paris-Saclay, \\ Thiverval-Grignon, France
}

Keywords: agroecology, best management practices, biotic and abiotic stresses, environmental sustainability, native plants

\section{Editorial on the Research Topic}

Agroecosystems Facing Global Climate Change: The Search for Sustainability

\section{OPEN ACCESS}

Edited by:

Vimala D. Nair,

University of Florida, United States

Reviewed by:

B. Mohan Kumar,

Nalanda University, India

Sotirios Archontoulis,

lowa State University, United States

*Correspondence:

José M. Mirás-Avalos jmirasa@udc.es

Specialty section:

This article was submitted to Agroecology and Ecosystem Services,

a section of the journal

Frontiers in Environmental Science

Received: 14 September 2018

Accepted: 24 October 2018

Published: 12 November 2018

Citation:

Mirás-Avalos JM and Baveye PC (2018) Editorial: Agroecosystems Facing Global Climate Change: The

Search for Sustainability.

Front. Environ. Sci. 6:135.

doi: 10.3389/fenvs.2018.00135
Climate change and variability in years to come should in principle affect agroecosystems worldwide due to impacts on plant growth and yield by elevated atmospheric $\mathrm{CO}_{2}$ concentration, higher temperatures, altered precipitation regimes, and increased frequency of extreme events, as well as modified weed, pest, and pathogen pressure (Altieri et al., 2015). In addition, because the diversity of agricultural systems has been reduced to maximize mono-crop yields under favorable conditions, it is possible that these systems will lack resilience when faced with changing climate (Isbell, 2015). These future prospects have prompted a new conscience about environmentally friendly agroecosystems, and policies are being actively promoted, which aim to prohibit or at least limit pesticide use, as well as promote the adoption of best management practices (Lamichhane et al., 2016). Furthermore, consumers tend to shift to healthy products, away, sometimes, from less healthy ones resulting from industrialized agriculture (Sogari et al., 2016). In this context, researchers have endeavored to find and establish the best options that farmers could adopt to preserve natural resources such as soil and water while maintaining the yields and economic benefits of traditional practices (Fleming and Vanclay, 2010; Iglesias and Garrote, 2015; van der Laan et al., 2017).

In this general context, this Research Topic aims to present recent scientific progress concerning agricultural practices that allow agroecosystems to cope with the new challenges imposed by global change. The Research Topic comprises 11 articles, including 6 Original Research articles, 2 Reviews, 2 Perspective articles, and 1 Method article. No doubt there are many more issues that could fit under the very broad scope of the Research Topic, but the articles gathered already cover a sizeable range of subjects, from novel agricultural practices to biodiversity, crop performance, and soil properties.

Soil is a non-renewable resource that deserves special attention in the context of sustainable agriculture under climate change. In this Research Topic, two articles focus on this important resource. Gao et al. study the effects that afforestation may have on soil inorganic carbon (SIC) sequestration in Northwest China. This form of carbon is the dominant one in arid and semiarid areas; therefore, a subtle fluctuation of SIC pool can alter the regional carbon budget. These authors found that the SIC pool increased after afforestation for 30 years, doubling the SIC amount observed in sandy soils, indicating the high potential of afforestation for sequestering carbon. In addition, Bhat et al. compare the soil biological activity, focusing on phosphorus availability for crops, under long-term organic management vs. conventional agriculture in central India. They 
reported that organic systems possessed equal capabilities of supplying phosphorus for crop growth as conventional systems due to a higher biological activity.

An interesting perspective article by Nair et al. highlights the potentialities and limitations that biochar application has for sustainable agriculture. Over the last decade, many authors have promoted the idea that applying biochar or agrichar to soils presents a number of possible benefits, among which are the reduction of bulk density, enhancement of water-holding capacity, and stabilization of organic matter. Nevertheless, the merits of biochar remain extremely controversial (e.g., SánchezGarcía et al., 2014; Baveye et al., 2018). In that respect, Nair et al. point out that several problems and bottlenecks remain to be addressed before one could consider widespread production and use of biochar. The current state of knowledge is based largely on limited small-scale studies under laboratory and greenhouse conditions. Properties of biochar vary with both the feedstock from which it is produced and the method of production. The availability of feedstock as well as the economic merits, energy needs, and potential environmental risks of its large-scale production and use remain to be investigated. Nevertheless, Nair et al. argue in favor of the viewpoint that biochar could play a significant role in facing the challenges posed by climate change and threats to agroecosystem sustainability.

The reduction of diversity in agroecosystems in a climate change context is the subject of three articles within this Research Topic. First, Nair et al. highlights the virtues of multi-strata tree + crop (MTC) systems. These systems are based on niche complementarity among species. This implies that MTC systems are structurally and functionally more complex than crop or tree monocultures, resulting in greater efficiency for capturing and using resources (light, water, nutrients). Ecosystem services, future scenarios and directions of MTC systems are clearly described in this thought-provoking article. Second, Shelef et al. review the value of native plants and local production as a means to promote food diversity and agricultural resilience. These authors used the example of producing pine nuts in the Western United States to illustrate their proposal to support local food production in an ecologically sustainable manner. Third, Chedraoui et al. review in detail the literature devoted to Capparis spinosa (L.), a xerophilous species with a broad range of benefits and potentialities for agriculture in Eastern Mediterranean countries. This review provides information about the origin, distribution, taxonomy, genetics, cultivation, phytochemical composition of this species, as well as some of its traditional uses. Along this line of preserving biodiversity, Arheimer et al. are concerned with the decrease of snowy periods in northern Europe, which could lead to diversity losses in riparian mixed forests that are flooded during some periods of the year. These authors propose, through a modeling approach, to use artificial floods to preserve diversity in these ecosystems;

\section{REFERENCES}

Altieri, M. A., Nicholls, C. I., Henao, A., and Lana, M. A. (2015). Agroecology and the design of climate change-resilient farming systems. Agron. Sustain. Dev. 35, 869-890. doi: 10.1007/s13593-015-285-2 however, several factors, both technical and economic, restrict the practical implementation of this proposal.

Crop performance under different conditions has been addressed in two articles within this Research Topic. First, Li et al. are interested in assessing the extent of soybean nitrogen fixation under elevated $\mathrm{CO}_{2}$ conditions, since these could limit crop performance due to nitrogen limitations. These conditions increase the ability of plants to take up nitrogen by facilitating root proliferation and nodule growth. Second, the use of marginal lands for growing sorghum for bioethanol production is the subject of the article by Tang et al. They conclude that energy sorghum grown on marginal lands has a very low potential for ethanol production and, therefore, offers a lower possibility for commercial feedstock supply when compared to that grown on regular croplands. However, screening suitable varieties may improve the growth of sorghum and its chemical properties for ethanol production on marginal lands.

From an economic perspective, Riar et al. present a diagnosis of biophysical and socio-economic factors influencing the choice to adopt organic or conventional systems for cotton production. Organic farmers are motivated by the sustainability of cotton production and growing food without pesticides, whereas conventional farmers are sensitive to their reputation in the community.

Finally, in an interesting methodological article, Kundel et al. explain the design and the advantages of a new model of rainoutshelters for climate change experiments in agroecosystems. These devices prove able to sustain heavy weather and could be used in agricultural fields where management operations require the removal of the rainout-shelters. Moreover, they prevent common artifacts that occur when one uses other devices.

Clearly, the 11 articles composing this Research Topic only begin to scratch the surface of a very broad area of research (as noted by the absence of articles devoted to soil organic carbon), which will undoubtedly become the focus of increasing attention, as time goes by and the effects of global climate change on agroecosystems become more pronounced and noticeable. In this context, it is our hope that this Research Topic will contribute in some measure to fostering a healthy debate on whither the research should be heading in years to come.

\section{AUTHOR CONTRIBUTIONS}

JM-A conceived and coordinated this Research Topic. JM-A and PCB read the various articles included in the RT, contributed to the writing of this editorial, and jointly approved it.

\section{ACKNOWLEDGMENTS}

The editors want to express their profound gratitude to all the reviewers for their valuable contributions, which helped to achieve high standards for the contributed papers.

Baveye, P. C., Berthelin, J., Tessier, D., and Lemaire, G. (2018). The "4 per
1000" initiative: a credibility issue for the soil science community? Geoderma
309(Suppl. C), 118-123. doi: $10.1016 /$ j.geoderma.2017.05.005
Fleming, A., and Vanclay, F. (2010). Farmer responses to
climate change and sustainable agriculture a review. 
Agron. Sustain. Dev. 30, 11-19. doi: 10.1051/agro/20 09028

Iglesias, A., and Garrote, L. (2015). Adaptation strategies for agricultural water management under climate change in Europe. Agric. Water Manage. 155, 113-124. doi: 10.1016/j.agwat.2015.03.014

Isbell, F. (2015). Agroecosystem diversification. Nat. Plants 1:15041. doi: 10.1038/NPLANTS.2015.41

Lamichhane, J. R., Dachbordt-Saaydeh, S., Kudsk, P., and Messéan, A. (2016). Toward a reduced reliance on conventional pesticides in European agriculture. Plant Dis. 100, 10-24. doi: 10.1094/PDIS-05-15-0574-FE

Sánchez-García, M., Roig, A., Sánchez-Monedero, M. A., and Cayuela, M. L. (2014). Biochar increases soil $\mathrm{N}_{2} \mathrm{O}$ emissions produced by nitrificationmediated pathways. Front. Environ. Sci. 2:25. doi: 10.3389/fenvs.20 14.00025

Sogari, G., Mora, C., and Menozzi, D. (2016). Factors driving sustainable choice: the case of wine. Br. Food J. 118, 632-646. doi: 10.1108/BFJ-04-2015-0131 van der Laan, M., Bristow, K. L., Stirzaker, R. J., and Annandale, J. G. (2017). Towards ecologically sustainable crop production: a South African perspective. Agric. Ecosys. Environ. 236, 108-119. doi: 10.1016/j.agee.2016. 11.014

Conflict of Interest Statement: The authors declare that the research was conducted in the absence of any commercial or financial relationships that could be construed as a potential conflict of interest.

Copyright (c) 2018 Mirás-Avalos and Baveye. This is an open-access article distributed under the terms of the Creative Commons Attribution License (CC BY). The use, distribution or reproduction in other forums is permitted, provided the original author(s) and the copyright owner(s) are credited and that the original publication in this journal is cited, in accordance with accepted academic practice. No use, distribution or reproduction is permitted which does not comply with these terms. 